\title{
Urinary Excretion Post Inhalation Method to Correlate Inhaler Technique with Disease Control in Patients with Obstructive Pulmonary Diseases Using Own Metered Dose Inhaler (MDI)
}

\author{
ethirajan nandagopal ${ }^{1}$, Sumithra $\mathrm{M}^{1}$, and N Meenakshi ${ }^{2}$ \\ ${ }^{1}$ VISTAS \\ ${ }^{2}$ Chettinad Health City
}

April 1, 2021

\begin{abstract}
Objectives: Correct use of inhaler devices is critical in ensuring the optimal lung bioavailability of the inhaled drug. The study aimed to assess inhaler technique used in patients with using metered-dose inhalers (MDI) by correlating with urinary salbutamol excretion post inhalation and its correlation with disease control. Methods: Thirty patients with obstructive pulmonary diseases attending outpatients' services inhaled two doses of salbutamol $100 \mu \mathrm{g}$ and urine samples were collected after 30 min. Inhaler technique scores were assessed using a standardized 8-point checklist. The 30-minute concentration of urinary salbutamol is then correlated with inhaler technique scores and control status of the disease. Key findings: The mean age of the subjects was $60.8(\mathrm{SD} \pm 9.338)$. The mean $(\mathrm{SD}) 30 \mathrm{~min}$ urinary salbutamol concentration was $3.6 \pm 1.6 \mu \mathrm{g} / \mathrm{ml}$. The mean concentration of salbutamol was found to be $2.3 \mu \mathrm{g} / \mathrm{ml}(\mathrm{n}=1), 2.3 \mu \mathrm{g} / \mathrm{ml}(\mathrm{n}=5), 3.1 \mu \mathrm{g} / \mathrm{ml}(\mathrm{n}=7), 3.9 \mu \mathrm{g} / \mathrm{ml}(\mathrm{n}=8), 4.7 \mu \mathrm{g} / \mathrm{ml}(\mathrm{n}=5), 5.3$ $\mu \mathrm{g} / \mathrm{ml}(\mathrm{n}=3)$, and $5.0 \mu \mathrm{g} / \mathrm{ml}(\mathrm{n}=1)$ among patients performing $1,2,3,4,5,6,7,8$ steps correctly, respectively. There was a statistically significant correlation $(\mathrm{p}=0.028)$ witnessed between the mean 30 min urinary salbutamol concentration and total correct steps. The frequency of exacerbation, use of antibiotics, and oral corticosteroids (OCS) were more in patients with poor inhaler technique scores, although statistical significance was achieved only for frequency of antibiotics use ( $\mathrm{p}=0.032$ ). Conclusions: The 30 min salbutamol urinary concentration evaluation may help to identify patients who were underdosed due to poor handling of inhaler devices. Being a complex procedure, it can at least be initiated in patients reporting frequent exacerbations, hospitalization, and those who need multiple drugs for disease control.
\end{abstract}

\begin{abstract}
Objectives: Correct use of inhaler devices is critical in ensuring the optimal lung bioavailability of the inhaled drug. The study aimed to assess inhaler technique used in patients with using metered-dose inhalers (MDI) by correlating with urinary salbutamol excretion post inhalation and its correlation with disease control.

Methods : Thirty patients with obstructive pulmonary diseases attending outpatients' services inhaled two doses of salbutamol $100 \mu \mathrm{g}$ and urine samples were collected after $30 \mathrm{~min}$. Inhaler technique scores were assessed using a standardized 8-point checklist. The 30-minute concentration of urinary salbutamol is then correlated with inhaler technique scores and control status of the disease.
\end{abstract}

Key findings : The mean age of the subjects was 60.8 (SD \pm 9.338 ). The mean (SD) 30 min urinary salbutamol concentration was $3.6 \pm 1.6 \mu \mathrm{g} / \mathrm{ml}$. The mean concentration of salbutamol was found to be $2.3 \mu \mathrm{g} / \mathrm{ml}$ $(\mathrm{n}=1), 2.3 \mu \mathrm{g} / \mathrm{ml}(\mathrm{n}=5), 3.1 \mu \mathrm{g} / \mathrm{ml}(\mathrm{n}=7), 3.9 \mu \mathrm{g} / \mathrm{ml}(\mathrm{n}=8), 4.7 \mu \mathrm{g} / \mathrm{ml}(\mathrm{n}=5), 5.3 \mu \mathrm{g} / \mathrm{ml}(\mathrm{n}=3)$, and $5.0 \mu \mathrm{g} / \mathrm{ml}$ $(\mathrm{n}=1)$ among patients performing $1,2,3,4,5,6,7,8$ steps correctly, respectively. There was a statistically significant correlation $(\mathrm{p}=0.028)$ witnessed between the mean 30 min urinary salbutamol concentration and 
total correct steps. The frequency of exacerbation, use of antibiotics, and oral corticosteroids (OCS) were more in patients with poor inhaler technique scores, although statistical significance was achieved only for frequency of antibiotics use $(\mathrm{p}=0.032)$.

Conclusions : The 30 min salbutamol urinary concentration evaluation may help to identify patients who were underdosed due to poor handling of inhaler devices. Being a complex procedure, it can at least be initiated in patients reporting frequent exacerbations, hospitalization, and those who need multiple drugs for disease control.

Keywords : obstructive pulmonary disease; optimal inhaler technique; metered inhaler device; urinary salbutamol concentration; disease control.

\section{Introduction}

Inhaled bronchodilators and inhaled corticosteroids were the mainstays in the management of obstructive pulmonary diseases. These agents were delivered through different inhaler devices as it was considered to be the best route to administer for better safety and efficacy outcomes. ${ }^{1,2}$ Unlike systemic drugs, inhaled medicines are rapidly directed towards the airways, allowing for rapid onset. Some of the commonly used delivery devices were nebulizers, pressurized metered-dose inhalers (pMDI), dry powder inhalers (DPI), or Soft Mist inhalers were the commonly used devices. pMDI was introduced in 1950 and it became very popular and widely used for inhalation therapy in patients with obstructive pulmonary diseases. The coordination between inhalation and actuation of inhaler was an important issue ${ }^{3}$. There was an ocean of studies published in the last few decades assessing the importance of optimal inhaler technique use and its significance over the control status of the disease. Appropriate use of inhaler devices is very important for both asthma and COPD management as it results in compromised therapeutic outcomes leading to inadequate control of symptoms. ${ }^{4,5,6,7}$ Inhalation therapy using a valve holding chamber MDI has been shown to play a key role in the treatment of asthmatic patients as they encourage patients to breathe out of a drug pool. ${ }^{3,8}$. However, several studies concluded that a significant proportion of patients continue to use their inhaler devices incorrectly. ${ }^{9,10}$

For many years, measurements of pulmonary lung function (PFT) have been used to compare efficacy. Besides the evaluation of variations in systemic bioavailability, the concentration of the salbutamol excreted in the urine post 30 minutes of inhalation is determined and correlated with the amount of drug delivered to the lungs. ${ }^{11}$ The assessment of the relative bioavailability of salbutamol in the lung by obtaining a sample of urine 30 minutes after inhalation is reproducible, clear, and effective. ${ }^{12}$ The benefits of this approach compared to others are the use of a patient's own inhaler, no need for either the ingestion of charcoal or the use of a radiolabelled inhaler marker. The 30-minute urinary salbutamol concentration method may also be used concomitantly with measurements of lung function to demonstrate the association between improved deposition and enhanced spirometry. ${ }^{11}$ Only a few studies employed 30 min salbutamol urinary excretion post inhalation pharmacokinetic method to determine lung bioavailability of inhaler drugs, compare inhaler medications and devices in healthy volunteers, and only study in asthma patients. ${ }^{11-15}$ The aim of this paper is, therefore, to evaluate the urinary salbutamol concentration as a measure of relative bioavailability to the lung within the first 30 minutes after inhalation and correlate it with the total inhaler scores assessed through a standard questionnaire and control status of the disease.

\section{Method}

\section{Study Participants}

The study was conducted in the department of respiratory medicine, Chettinad Hospital. Thirty patients with obstructive pulmonary diseases who attend outpatient services at the department of respiratory medicine between August 2019 to March 2020 were enrolled in the study. Inclusion criteria for the study: diagnosis of COPD by the physician, prescribed to take salbutamol through metered-dose inhaler salbutamol at least for the previous 12 months. Patients who were using other inhaler devices other than MDI and those who do not have to follow up details at least for the previous 12 months were excluded. All eligible patients were 
enrolled in the study after obtaining informed consent.

\section{Sample Collection}

Subjects inhaled $2 \times 100 \mu \mathrm{g}$ salbutamol (nominal dose $200 \mu \mathrm{g}$ ). Salbutamol was delivered via their own MDI device. The inhaler delivered a nominal dose of $100 \mu \mathrm{g}$ per actuation. Subjects emptied their bladders immediately before drug administration and then urine samples were collected $30 \mathrm{~min}$ after the inhaled doses. The collected urine samples were recorded and stored at $-20{ }^{\circ} \mathrm{C}$ before analysis. A previously validated, sensitive high-performance liquid chromatography (HPLC) method was used to measure urine concentrations of salbutamol. ${ }^{16}$ Subjects did not drink alcohol or caffeine-containing beverages for $12 \mathrm{~h}$ before or $24 \mathrm{~h}$ after treatment. Demographic details like age, sex, disease characteristics were collected from each recruited patient. The study was approved by the Institutional Ethics Committee of the University (525/IHEC/3-19).

\section{Development of Checklists for Assessing Inhaler Technique}

The checklist for Metered-dose inhaler (MDI) was extracted from COPD guidelines ${ }^{17}$, 18 , and published literature. ${ }^{19-21}$ The use of inhaler devices was quantitatively assessed by assigning a score to each correct step. We allocated equal weightage and assigned 1 point to each of the total 8 steps (Appendix 1).

\section{Data analysis}

Data were entered in Microsoft excel and the same was analyzed using a statistical package for social sciences SPSS version 20.0 (IBM Corporation, Armonk, NY, USA). Statistical comparisons were made using percentile and mean differences. Descriptive statistics calculated for background variables. Since the data do not follow a normal distribution, the Kruskal Wallis test (Non-parametric) was performed to determine the association between the concentration of salbutamol and other background characteristics. Statistical significance was set at a p-value [?] of 0.05 .

\section{Results}

A total of thirty patients with a mean age of $60.8+-9.3$ years were enrolled in the study and $90 \%(\mathrm{n}=27)$ were male and $10 \%(\mathrm{n}=3)$ were female participants. On assessing the severity of COPD, there were $3.3 \%, 33.3 \%$, $50 \%$, and $13.3 \%$ of cases with mild, moderate, severe COPD, and very severe COPD, respectively among the study participants. All urine $\mathrm{pH}$ values were in the range 4-5-6-5. There were only $10 \%$ of patients reported no exacerbation and $90 \%$ of them had at least one exacerbation in the last year. Also, there were $16.7 \%$ of cases required hospitalization once, and $3.3 \%$ of cases required hospitalization twice in the last one-year duration. Only $23.3 \%$ of study participants were not taken an antibiotic course in the past year.. Also, only $16.7 \%$ of cases did not receive any OCS in the past year whereas $83.3 \%$ of cases received at least one short course of OCS in the past one-year duration.

Mean urine concentration of salbutamol concerning total correct steps were shown in Graph 1. The mean concentration of salbutamol was found to be $2.3 \mu \mathrm{g} / \mathrm{ml}(\mathrm{n}=1), 2.3 \mu \mathrm{g} / \mathrm{ml}(\mathrm{n}=5), 3.1 \mu \mathrm{g} / \mathrm{ml}(\mathrm{n}=7), 3.9 \mu \mathrm{g} / \mathrm{ml}$ $(\mathrm{n}=8), 4.7 \mu \mathrm{g} / \mathrm{ml}(\mathrm{n}=5), 5.3 \mu \mathrm{g} / \mathrm{ml}(\mathrm{n}=3)$, and $5.0 \mu \mathrm{g} / \mathrm{ml}(\mathrm{n}=1)$ among cases who performed two, three, four, five, six, seven and eight steps correctly, respectively.

\section{Graph 1: Mean 30-minute urinary concentration of salbutamol concerning total correct steps}

The concentration of 30-minute urinary salbutamol concentration concerning exacerbation, antibiotic, and OCS use was shown in Table 1. On assessing the salbutamol concentration concerning episodes of exacerbation, the mean urinary concentration of salbutamol was found to be $5.3 \mu \mathrm{g} / \mathrm{ml}, 4.5 \mu \mathrm{g} / \mathrm{ml}, 3.1 \mu \mathrm{g} / \mathrm{ml}$, $3.2 \mu \mathrm{g} / \mathrm{ml}, 3.3 \mu \mathrm{g} / \mathrm{ml}$, and $0.5 \mu \mathrm{g} / \mathrm{ml}$ among cases with exacerbation of zero episodes, one, two, three, four, and six episodes of exacerbations, respectively. The mean difference in concentration of salbutamol and exacerbations in the past year was found to be statistically insignificant. $(\mathrm{p}=0.192)$

The mean concentration of salbutamol was found to be $5.3 \mu \mathrm{g} / \mathrm{ml}, 3.3 \mu \mathrm{g} / \mathrm{ml}, 3.3 \mu \mathrm{g} / \mathrm{ml}, 3.5 \mu \mathrm{g} / \mathrm{ml}, 1.7 \mu \mathrm{g} / \mathrm{ml}$, and $0.5 \mu \mathrm{g} / \mathrm{ml}$ among cases with antibiotic use of zero courses (not taken antibiotics), one, two, three, four and five courses of antibiotic use, respectively. On assessing the difference in the mean concentration of 
salbutamol and a short course of OCS use, the mean concentration of salbutamol was found to be $5.0 \mu \mathrm{g} / \mathrm{ml}$, $4.3 \mu \mathrm{g} / \mathrm{ml}, 3.4 \mu \mathrm{g} / \mathrm{ml}, 3.1 \mu \mathrm{g} / \mathrm{ml}$, and $1.3 \mu \mathrm{g} / \mathrm{ml}$ among cases with short course OCS use of zero courses (not taken OCS), one, two, three and four courses of antibiotic use, respectively.

Table 1: Concentration of 30-minute urinary salbutamol concerning exacerbation, antibiotic, and OCS use

\section{Discussion}

The concentration of salbutamol in the plasma was low following inhalation therapy delivery devices. LEWIS et al reported a median plasma concentration of $7.4 \mu \mathrm{g} / \mathrm{l}$ of salbutamol after one hour of inhalation through a nebulizer. ${ }^{22}$ At the same time, the concentration of salbutamol in urine following inhalation is much higher which becomes convenient to get detected through assay. Salbutamol is excreted majorly through the kidneys. The basic properties of salbutamol are unlikely to exhibit significant $\mathrm{pH}$-dependent clearance through the renal system, especially $\mathrm{pH}$ values below 6.5 of urine. ${ }^{23}$

Hindle and colleagues established that the increased initial recovery of the drug is due to the fact the salbutamol delivered to the lungs was rapidly absorbed through alveoli and then eliminated unchanged by the kidneys. ${ }^{14}$ They employed this simple non-invasive method in 10 healthy subjects to determine an optimal inhaler technique with commercially available metered-dose inhalers (MDI) comparing different respiratory maneuvers. Later, this method has been used to compare the delivery of drugs to the lungs through different devices $^{24}$ and evaluate the effect of inhalation rate. ${ }^{25}$ For the first time we employed this method to study the inhaler technique use among patients with obstructive pulmonary disease and correlate it with the control status of the disease.

The proportion of patients making inhaler errors differs widely between the studies and the estimated of those making inhaler errors ranges up to $90 \%{ }^{26,27}$. The strong correlation between inhaler device use and disease status is established through multiple studies. Incorrect use of devices may have an impact on the effectiveness of the drug delivery further leading to poor treatment outcomes. ${ }^{17}$ On the other side, improving inhaler technique through training led to significant improvement in the number of attacks $(\mathrm{p}<0.001)$, emergency applications, hospitalizations ( $\mathrm{p}>0.05)$, and overall quality of life. ${ }^{28}$

Over half of the COPD patients were unable to use the device correctly. ${ }^{1}$ In a systematic reviewing 144 published articles on inhaler technique use and the errors made by the patients, only a low proportion (31\%) of patients could demonstrate the correct inhaler technique. ${ }^{29}$ This concludes the correct use of inhaler technique has not improved over the past 40 years despite different approaches. In the present study, only 1 patient out of 30 could perform all the 8 steps correctly and half of them scored only [?] 5 steps correct.

The mean urine concentration of salbutamol was found to be $3.6 \pm 1.6 \mu \mathrm{g} / \mathrm{ml}$ and the highest mean urinary concentration of salbutamol was found in patients performing all eight steps correctly. The mean difference in urine concentration of salbutamol was found to be steadily increasing with an increase in the total number of correct steps and it was found to be statistically significant $(\mathrm{p}=0.028)$. The mean urinary concentration of salbutamol was negligible $(0.5 \mu \mathrm{g} / \mathrm{ml})$ in patients reported with the highest exacerbation frequency. Similar results were reported by Molimard and colleagues, that those making critical errors in handling the device were likely to experience a two-fold increase in severe exacerbations than those who handle their devices without critical errors (3.3\% versus $6.9 \%$ respectively). ${ }^{7}$

Previous studies reported poor inhaler technique led to inadequate drug delivery to the lungs can end up in an unintentional form of non-adherence. COHORT investigators reported unintentional nonadherence through poor metered-dose inhaler technique associated with overuse of ICS in mild to moderate COPD patients. ICS use was more common among patients with poor MDI technique (44\%) than those with adequate technique $(25 \%) .{ }^{30}$ We noted an inverse relationship between the prescribed frequency of short courses of OCS and antibiotics with a mean concentration of 30-minute urinary salbutamol over the previous 12 months. The mean difference in 30-minute urinary concentration of salbutamol and antibiotic use in the past year was found to be statistically significant. $(\mathrm{p}=0.032)$. 


\section{Conclusion}

The study reiterated the fact that poor inhaler technique is a common problem with patients on inhaler therapy. Spirometry is a simple, convenient tool and widely available instructed where measuring urinary concentration through HPLC is a tedious and complex process which makes it unlikely to be accepted to use on a routine basis in a clinical setup. Assessing the optimal inhaler technique through measurement of urinary salbutamol concentration is likely to be better than measuring the pulmonary function through spirometry alone but it comes with the cost. The 30-minute urinary concentration of salbutamol was linear with inhaled dose and the results of this study witnessed it to correlate with the control status of the disease. It may help to identify patients who were under-dosed due to poor handling of inhaler devices and provide appropriate training and monitoring. Understanding the complexity coupled with the procedure, this method can at least be initiated in patients reporting frequent exacerbations, hospitalization, and those who need multiple drugs for disease control.

\section{Acknowledgements}

We would like the thank medical postgraduates and respiratory therapist for their support during the conduct of the study.

\section{Conflict of Interest}

No conflict of interest

\section{Funding}

This research received no specific grant from any funding agency in the public, commercial, or not-for-profit sectors"

\section{References}

1. Molimard M, Raherison C, Lignot S, et: Chronic obstructive pulmonary disease exacerbation and inhaler device handling: real-life assessment of 2935 patients. Eur Respir J. 2017, 49:1601794. doi: 10.1183/13993003.01794-2016.

2. Sanchis J, Gich I, Pedersen S: Systematic review of errors in inhaler use: has patient technique improved over time?. Chest . 2016, 150:394-406. doi: 10.1016/j.chest.2016.03.041..

3. Hess DR. Aerosol delivery devices in the treatment of asthma.Respir Care . 2008, 53: 699-723.

4. Hesselink AE, Penninx BW, Wijnhoven HA, Kriegsman DM, van Eijk JT. Determinants of an incorrect inhalation technique in patients with asthma or COPD. Scand J Prim Health Care . 2001;19(4):255-60. doi: 10.1080/02813430152706792.

5. Pedersen S, Frost L, Arnfred T. Errors in inhalation technique and efficiency in inhaler use in asthmatic children. Allergy . 1986;41(2):118-24. doi: 10.1111/j.1398-9995.1986.tb00287.x.

6. Goren A, Noviski N, Avital A, Maayan C, Stahl E, Godfrey S, Springer C. Assessment of the ability of young children to use a powder inhaler device (Turbuhaler). Pediatr Pulmonol. 1994;18(2):77-80. doi: 10.1002/ppul.1950180204.

7. Molimard M, Raherison C, Lignot S, Depont F, Abouelfath A, Moore N. Assessment of handling of inhaler devices in real life: an observational study in 3811 patients in primary care. J Aerosol Med . 2003;16(3):249-54. doi: 10.1089/089426803769017613.

8. Connett GJ, Warde C, Wooler E, Lenny W: Use of budesonide in severe asthmatic aged 1-3 years. Arch Dis Child . 1993; 69:351-355. doi: 10.1136/adc.69.3.351.

9. Luczak-Wozniak K, Dabrowska M, Domagala I, Miszczuk M, Lubanski W, Leszczynski A, Krenke R: Mishandling of pMDI and DPI inhalers in asthma and COPD - repetitive and non-repetitive errors. Pulm Pharmacol Ther . 2018; 51:65- 2. doi: 10.1016/j.pupt.2018.06.002.

10. Crane MA, Jenkins CR, Goeman DP, Douglass JA: Inhaler device technique can be improved in older adults through tailored education: findings from a randomized controlled trial. NPJ Prim Care Respir Med . 2014, 24:14034. doi: 10.1038/npjpcrm.2014.34. 
11. Hindle M, Chrystyn H. Determination of the relative of salbutamol to the lung following inhalation. Br J Clin Pharmacol 1992; 34: 311-315. doi: 10.1111/j.1365-2125.1992.tb05921.x.

12. Tomlinson HS, Corlett SA, Chrystyn H. Dose-response relationship and reproducibility of urinary salbutamol excretion during the first $30 \mathrm{~min}$ after inhalation. Br J Clin Pharmacol. 2003; 56(2):225-7. doi: $10.1046 /$ j.1365-2125.2003.01864.x.

13. Hindle M, Chrystyn H: Relative bioavailability of salbutamol to the lung following inhalation using metered-dose inhalation methods and spacer devices. Thorax . 1994, 49: 549-553. doi: 10.1136/thx.49.6.549.

14. Hindle M, Newton DA, Chrystyn H. Investigations of an optimal inhaler technique with the use of urinary salbutamol excretion as a measure of relative bioavailability to the lung. Thorax . 1993 Jun;48(6):607-10. doi: 10.1136/thx.48.6.607.

15. Du XL, Zhu Z, Fu Q, Li DK, Xu WB. Pharmacokinetics and relative bioavailability of salbutamol metered-dose inhaler in healthy volunteers. Acta Pharmacol Sin . 2002 Jul;23(7):663-6.

16. Chege JK, Chrystyn H. Volumatic usage: some generic salbutamol metered-dose inhalers can be used. Thorax 1994;49: 1162-1163. doi: 10.1136/thx.49.11.1162.

17. Singh D, Agusti A, Anzueto A, Barnes PJ, Bourbeau J, Celli BR. Et al. Global Strategy for the Diagnosis, Management, and Prevention of Chronic Obstructive Lung Disease: the GOLD science committee report 2019. Eur Respir J . 2019;53(5):1900164. doi: 10.1183/13993003.00164-2019.

18. Ministry of Health. Vietnamese Guideline for Diagnosis and Treatment of Chronic Obstructive Pulmonary Disease. 2015. (No 2866/QĐ-BYT). Hanoi: Medical Publishing House; 2015.

19. Sanchis J, Corrigan C, Levy ML, Viejo JL; ADMIT Group. Inhaler devices - from theory to practice. Respir Med. 2013;107(4):495-502. doi: 10.1016/j.rmed.2012.12.007.

20. Batterink J, Dahri K, Aulakh A, Rempel C. Evaluation of the use of inhaled medications by hospital inpatients with chronic obstructive pulmonary disease. Can J Hosp Pharm . 2012;65(2):111-118. doi: 10.4212/cjhp.v65i2.1118.

21. Basheti IA, Armour CL, Bosnic-Anticevich SZ, Reddel HK. Evaluation of a novel educational strategy, including inhaler-based reminder labels, to improve asthma inhaler technique. Patient Educ Couns . 2008;72(1):26-33. doi: 10.1016/j.pec.2008.01.014.

22. Lewis LD, McLaren M, Essex E, Cochrane GM. Plasma concentrations of salbutamol in acute severe asthmatics. Aust N Z J Med . 1990;20(3):204-7. doi: 10.1111/j.1445-5994.1990.tb01019.x.

23. Horn CR, Essex E, Hill P, Cochrane GM. Does urinary salbutamol reflect compliance with the aerosol regimen in patients with asthma?Respir Med . 1989;83(1):15-8. doi: 10.1016/s0954-6111(89)80054-x.

24. Silkstone VL, Corlett SA, Chrystyn H. Determination of the relative bioavailability of salbutamol to the lungs and systemic circulation following nebulization. Br J Clin Pharmacol. 2002 Aug;54(2):115-9. doi: $10.1046 / \mathrm{j} .1365-2125.2002 .01632 . x$.

25. Chege JK, Chrystyn H. The relative bioavailability of salbutamol to the lung using urinary excretion following inhalation from a novel dry powder inhaler: the effect of inhalation rate and formulation.Respir Med . 2000 Jan;94(1):51-6. doi: 10.1053/rmed.1999.0692.

26. Al-Showair RA, Tarsin WY, Assi KH, Pearson SB, Chrystyn H. Can all patients with COPD use the correct inhalation flow with all inhalers and does training help? Respir Med . 2007;101:2395-401. doi: 10.1016/j.rmed.2007.06.008.

27. Lavorini F, Magnan A, Christophe Dubus J, Voshaar T, Corbetta L, Broeders M, Dekhuijzen R, Sanchis J, Viejo JL, Barnes P, et al. Effect of incorrect use of dry powder inhalers on management of patients with asthma and COPD. Respir Med. 2008;102:593-604. doi: 10.1016/j.rmed.2007.11.003.

28. Göriş S, Taşci S, Elmali F. The effects of training on inhaler technique and quality of life in patients with COPD. J Aerosol Med Pulm Drug Deliv . 2013;26(6):336-44. doi: 10.1089/jamp.2012.1017.

29. Sanchis J, Gich I, Pedersen S, Systematic review of errors in inhaler use: has patient technique improved over time? Chest. 2016; 150: 394-406. doi: 10.1016/j.chest.2016.03.041.

30. Griffith MF, Feemster LC, Donovan LM, Spece LJ, Krishnan JA, Lindenauer PK, McBurnie MA, Mularski RA, Au DH. Poor Metered-Dose Inhaler Technique Is Associated with Overuse of Inhaled Corticosteroids in Chronic Obstructive Pulmonary Disease. Ann Am Thorac Soc . 2019;16(6):765-768. 
doi: 10.1513/AnnalsATS.201812-889RL.

\section{Hosted file}

Table 1.pdf available at https://authorea.com/users/405253/articles/516261-urinary-excretionpost-inhalation-method-to-correlate-inhaler-technique-with-disease-control-in-patientswith-obstructive-pulmonary-diseases-using-own-metered-dose-inhaler-mdi

\section{Hosted file}

Graph 1.pdf available at https://authorea.com/users/405253/articles/516261-urinary-excretionpost-inhalation-method-to-correlate-inhaler-technique-with-disease-control-in-patientswith-obstructive-pulmonary-diseases-using-own-metered-dose-inhaler-mdi 